\title{
Reduction in paediatric burn admissions over 25 years, 1970-94
}

\author{
C Streeton, T Nolan
}

\begin{abstract}
Objective-To describe trends in burn admissions to a large paediatric burn centre, between 1970 and 1994.

Methods-Hospital records of the Royal Children's Hospital burns unit were audited for the years 1970-94 ( $n=4992)$, statewide hospital admissions identified from the Victorian Inpatient Minimum Database for the period, 1987-94 $(n=3353)$, and Victorian burn deaths ascertained from the Australian Bureau of Statistics $(n=163), 1970-94$.
\end{abstract}

Results-Between 1970 and 1994 there was a $66 \%$ reduction in the annual number of burn admissions to the Royal Children's Hospital, a similar reduction across the state, from 52.4 (95\% confidence interval (CI): 48 to 57$) / 100000$ in 1987 to 34.5 (95\% CI:31 to 38$) / 100000$ in 1994 $(p<0.05)$, and over a $40 \%$ fall in the mortality rate. Reductions occurred for all types of burns: scalds $60 \%$; flame burns $55 \%$; and contact burns $70 \%$, but at differing time periods corresponding to the introduction of product legislation, education programs, or changes in heating practices. There was no decline in beverage related scalds. The proportion of children admitted with severe burns increased over the 25 year period, probably reflecting changes in referral practice, while the average length of hospital stay steadily declined, independent of burn type or burn severity.

Conclusions-We believe these reductions reflect the effects of mandatory changes in sleepwear standards and regulations, modifications in heating practices, legislated improvements in the safety of household products, and to a lesser extent the effect of burn education prevention campaigns in the media, especially those directed towards hot water burn injuries among younger children.

(Injury Prevention 1997; 3: 104-109)

Keywords: burn injury; trends.

Burn injuries are an important cause of paediatric morbidity. In a study conducted by Nolan and Penny (1992), burns represented approximately $5 \%$ of emergency department injury presentations in children aged $0-14$ years in Victoria. During the same period, the hospital admission rate for burns and scalds was $165 / 100000$ children aged $0-14$ years. ${ }^{1}$

Evidence from studies in North America and Asia indicate that the burn rates in children have fallen steadily over the past decade. ${ }^{23}$ Although the general epidemiolog: patterns of burn injuries among children a known, large scale studies of burn trends has not been conducted.

In Victoria, substantial lifestyle, enviro禺 mental, and regulatory health care changes are factors that may have had an effect on childhood burns. These include changes $\overrightarrow{\mathrm{kg}}$ indoor heating devices, the introduction \&f clothing regulations and standards, and mote recently the introduction of smoke detectoriss These factors have not been evaluated, ner have the trends in Victorian hospital buth admissions been previously documented. The aim of this study was to provide a review of the epidemiology of burn injuries that result hospitalisation to the Royal Children's Hosp tal in Victorian children aged 0 to 14 betweege 1970 through to 1994.

\section{Subjects and methods}

Detailed hospital records of primary but admissions to the Royal Children's Hospiti burns unit were audited for the years 1976 through to 1994. Patients included in the studfy $(n=4992)$ were aged $0-14$ years. Information about patient age and sex; severity of bum (anatomic site, per cent of total body surface area (TBSA) burned, skin grafting and ouf come); length of hospitalisation; managemet of the burn injury, circumstances of the incident, including date and place of occus rence; type of injury (see Appendix 1) (scal $\vec{\Phi}$, flame, contact, electrical, chemical, radiatio friction, or flash burns); and ignition source (for example hot beverages, house fire, matcB. etc) were collected from the medical records where possible.

In the literature, three different categorios are used to define severe burns: those in which more than $10 \%$ of TBSA is affected; the anatomic site affected (for example head, neck, face); and the burn depth (that is superficia partial, or full thickness). ${ }^{4}$ The latter was nôt available.

Burn categories as defined in the Intern tional Classification of Diseases (ICD-9) we coded for comparative purposes. ${ }^{5}$ To reduce the amount of variability, where appropriate we analysed the data in three year average periods.

The criteria for hospitalisation of a burn patient to the Royal Children's Hospital burns unit have remained little unchanged during the 25 year period (E Julian Keogh, persong communication) ${ }^{6}$

We analysed statewide burn hospital admis sions of children aged $0-14$ years identified from the Victorian Inpatient Minimum Database (VIMD) for the period, 1987-94 $(n=3353)$. The VIMD is a statewide hospital morbidity data collection (ICD-9-DM). ${ }^{5}$ See 
Appendix 2 for ICD-9 CM codes used in the study.

We also analysed statewide burn mortality figures of children aged $0-14$ years $(n=163)$. Case numbers of deaths due to fire and flame (E890-E899) and by hot substances (E924) for Victoria (by state of registration), were obtained from the Australian Bureau of Statistics (ABS) for the period, 1970-94.

Victorian population figures were also obtained from the ABS by sex and age from 1971 to 1994 and used to calculate both age specific hospitalisation rates for the years 1987 to 1994 and age specific mortality rates for the years $1970-94 .^{7-9}$

\section{Results}

ROYAL CHILDREN'S HOSPITAL DATA RESULTS From 1970 to 1994 , there were 4992 paediatric burn admissions to the burns unit. In this period, there was a $66 \%$ fall in the annual number of admissions (fig 1). This decline appears to have gone through three phases: between 1970 to 1978 there was a fall of $33 \%$ (representing an average annual decline of $3.7 \%$ ), this was followed by a plateau between 1978 to 1991 , and then a further fall of $47 \%$ between 1991 to 1994 (an average annual

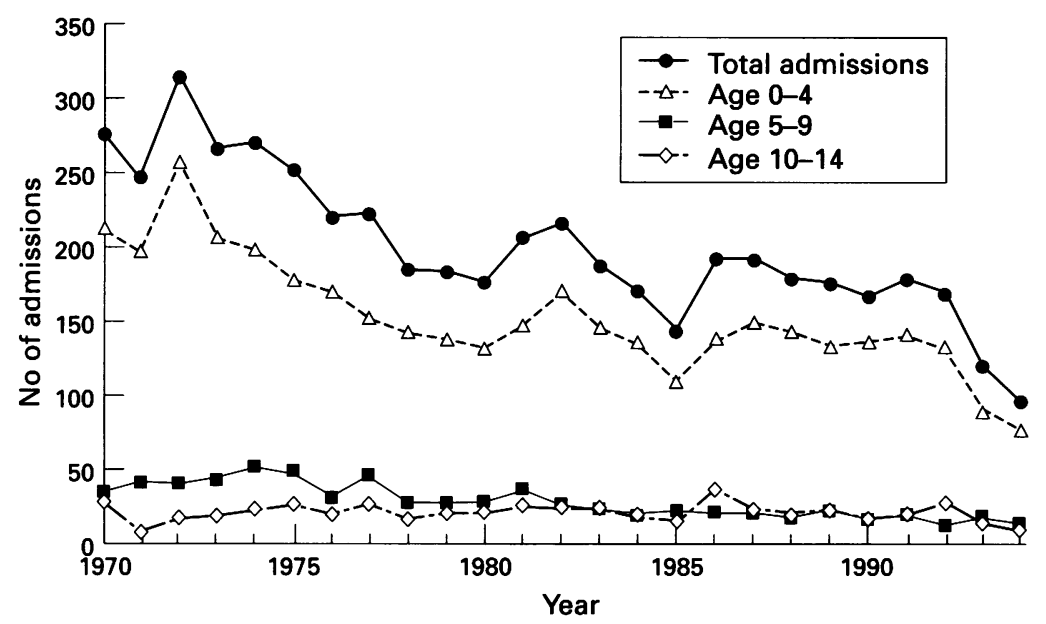

Figure 1 Number of burn admissions to the Royal Children's Hospital by age group, 197094.

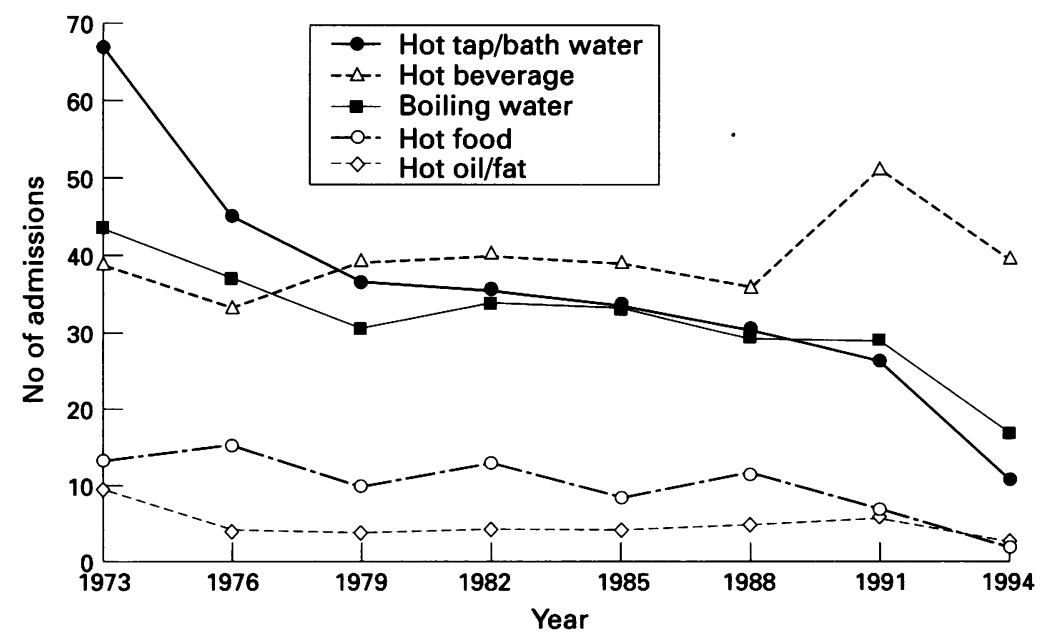

Figure 2 Average number of scald admissions by cause, Royal Children's Hospital, 197394. decline of $11.7 \%$ ).

The age distribution of all burn injuries changed little, with $74-81 \%$ of cases aged $0-4$ years. The decline in admissions in this age group paralleled the general decline (fig 1). The number of admissions for the 5-9 year age group fell by $80 \%$. In contrast, the number of 10-14 year age group admissions remained fairly constant (fig 1), so that the proportion of this age group's admissions doubled relative to the other two age groups. Males outnumbered females approximately $2: 1$ in every year, and there was a similar decline in the frequency of admissions for both sexes during the study period.

Scald, flame, and contact burns together contributed to over $95 \%$ of all burn admissions throughout the 25 year period. Scalds contributed to over $65 \%(n=3326)$ of all burn admissions. Since 1970 there has been a $60 \%$ reduction in the number of scald related admissions, from an average 186 in 1970 to 1972 to an average 75 in 1992 to 1994 . The trend for scald admissions paralleled that of all burn admissions.

The age distribution for scald burns has changed little, with $89 \%$ of cases being under 5 years of age in $1970,91 \%$ in 1983 , and $91 \%$ in 1994. Males were at a greater risk, accounting for $60 \%$ of all scalds in 1970 and $59 \%$ in 1994 .

We found an $83 \%$ reduction in hot bath or tap water scald related admissions over the 25 year period (fig 2). The proportion of these admissions compared with all scald admissions fell by $64 \%$. There was also a $61 \%$ decline in boiling water related scald admissions (that is kettle or stove top boiling water related injuries) (fig 2). In contrast, there was little change in the number of scald admissions resulting from cups of hot liquid (beverages) (fig 2).

Flame burns were the second major cause (18\%) of burns seen at the Royal Children's Hospital and the majority of these were caused by flammable liquids. There was a $57 \%$ reduction in flame burn admissions, from an average of 47 in 1970 to 1972 to an average of 20 in 1992 to 1994 , with a marked drop of $27 \%$ occurring between 1976 to 1981 .

As with scald admissions, the proportion of flame burns relative to all burn admissions remained fairly stable over the study period. Unlike scald burn admissions however, where children under 5 years contributed to the majority (75\%), flame burn admissions comprised similar proportions of the $0-4,5-9$, and 10-14 year olds. However, the number of flame burn admissions involving $0-4$ year olds and 5-9 year olds each fell by approximately $74 \%$ and $70 \%$ respectively, while the number of 10-14 year old admissions actually increased by $10 \%$ (fig 3).

A reduction of $88 \%$ was observed in the number of flame burn admissions associated with the ignition of clothing by indoor heating systems. There was a progressive and steep reduction initially, with the decline slowing a little since 1989 (fig 4). Medical records did not describe clothing type sufficiently well to reliably calculate the proportion accounted for 
by sleepwear. House fires contributed only $4 \%$ of flame burn admissions in $1973-5,10 \%$ in $1988-90$, and $5 \%$ in $1993-4$.

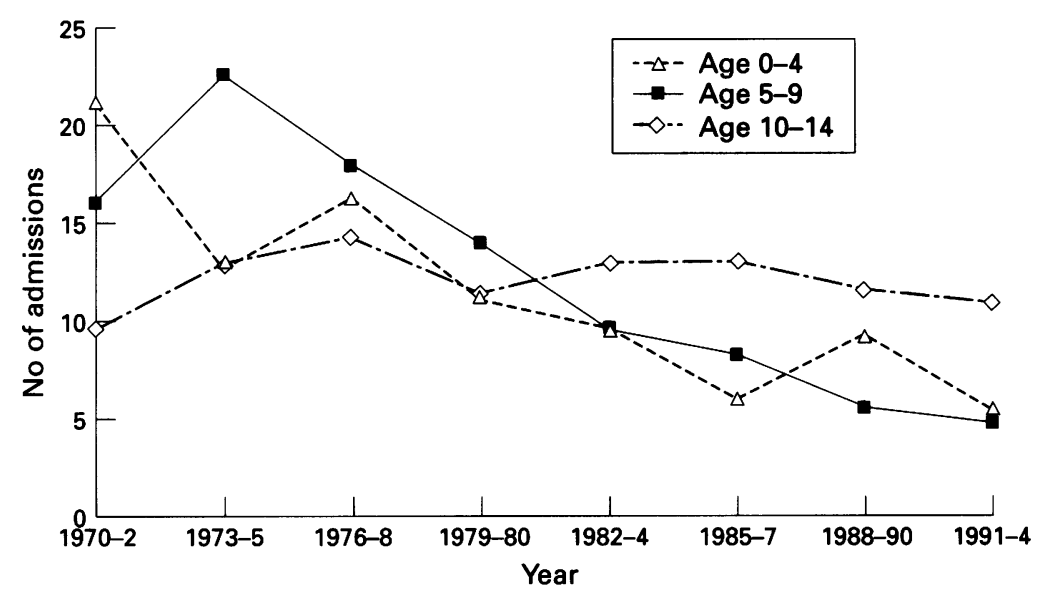

Figure 3 Average number of flame burn admissions to the Royal Children's Hospital by age group, 1970-94.

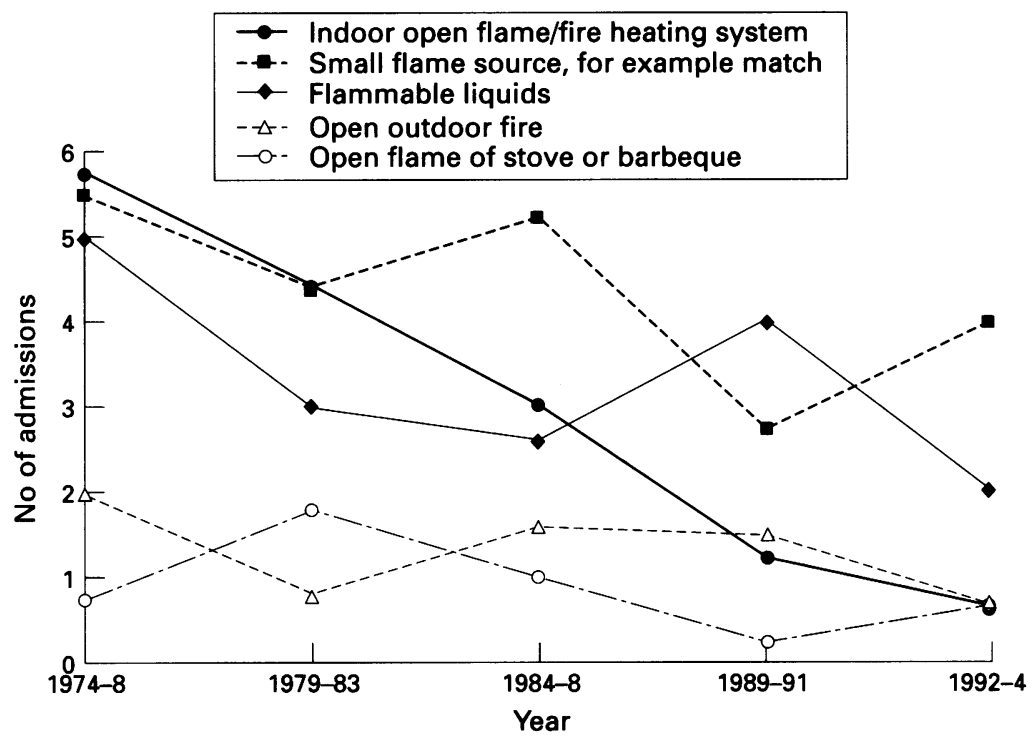

Figure 4 Average number of ignited clothing flame burn admissions to the Royal Children's Hospital by source of ignition, 1974-94.

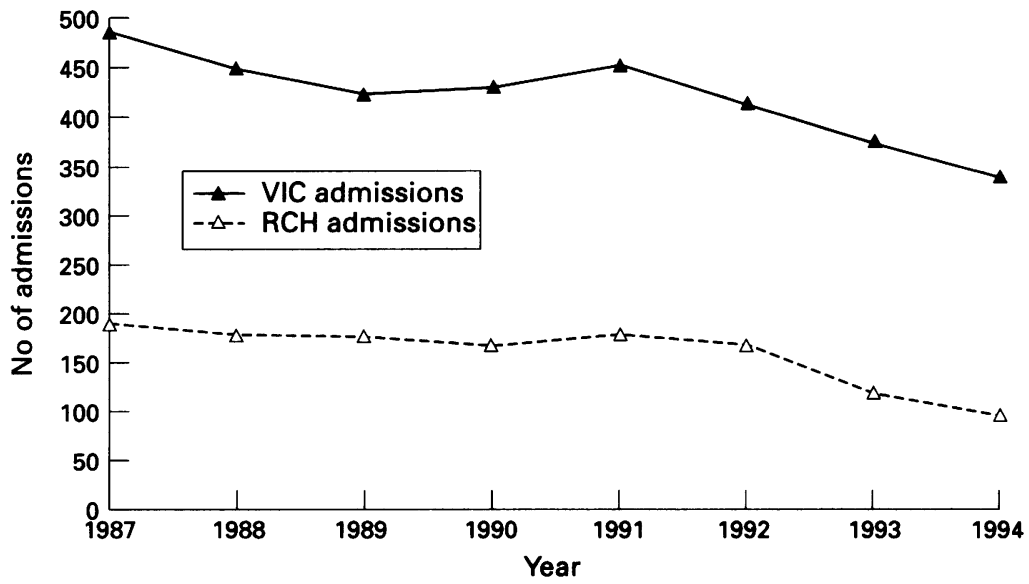

Figure 5 Victorian State burn admissions (VIC), children aged 0-14 years, related to those admitted to the Royal Children's Hospital (RCH), 1987-94. (Note different scale of ordinate compared with fig 1.)
As with the substantial reductions in scald and flame burn admissions, there was also a considerable reduction in contact burn admissions. These fell by $70 \%$, from an average of 3E. admissions in 1970-2, to an average of nineo admissions in 1993-4. There was a progressive reduction since 1970 , with $50 \%$ occurring between 1970 to 1978 .

The major source of contact burns were electric bar radiators or glass fronted heaters음 In 1970 , there were 17 bar radiator or heate 5 associated contact burn admissions. In $1994^{\circledR}$ there were only two, a fall of $88 \%$. Throughou每 the 25 year period, the $0-4$ year age group were most at risk of a contact burn admission; whether male or female.

Radiation, chemical, friction, and flash burns contributed only $5 \%$ of all admissions It is notable that there were only 23 burriv injuries resulting from firecrackers, all of whicho occurred before 1982, the year all firewor availability to the public was banned.

Despite all these encouraging trends, the proportion of children admitted with severe burns has increased over the 25 year period. In $1970,25 \%$ of burn admissions to the Royato Children's Hospital had $10 \%$ or more TBSA burned compared with $45 \%$ in 1994 . Anato? mical site was also used as a marker of severity in 1970, the head, face, and/or neck were

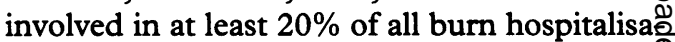
tions, increasing to $26 \%$ in 1994 . Flame burns were the major contributor to the rise in th $\vec{E}$ proportion of severe burn and accounted for 25 (93\%) of the 27 deaths during the study period.

While the proportion of burned children admitted with severe burns has increased, the average length of hospital stay has steadily declined from an average 16 days in the earl 1970 s to an average of seven days in the mid产 1990 s, independent of burn type or severity.

\section{VIMD RESULTS}

Between 1987 and 1994, 3353 children age were identified from the VIMD as being hospitalised with a scald, flame, contact, o chemical burn injury in Victoria. There was substantial reduction $(31 \%)$ in the number of burn admissions across the state (average annual decline of $3.8 \%$ ) (fig 5). Boys under years had the highest incidence of burfw admissions. There was an excess of boys if every age group.

The average burn admission rate for th eight year period dropped by $33 \%(p<0.05)^{2}$ (table 1) during which time the Royal Chilodren's Hospital admitted a fairly constant 35\% share of all burn hospitalisations (fig 5). Th admission rate was three times greater fof children aged $0-4$ but decreased (30\% parallel with the total, constituting almose $80 \%$ of the toal group hospitalised $(n=2570)$ A similar trend was observed at the Royd Children's Hospital. Of particular interest was the drop of nearly $52 \%$ in the 5-9 year age group $(p<0.05)$ (table 1$)$. There was no significant change in the incidence of burns for the older age group despite a small drop in 


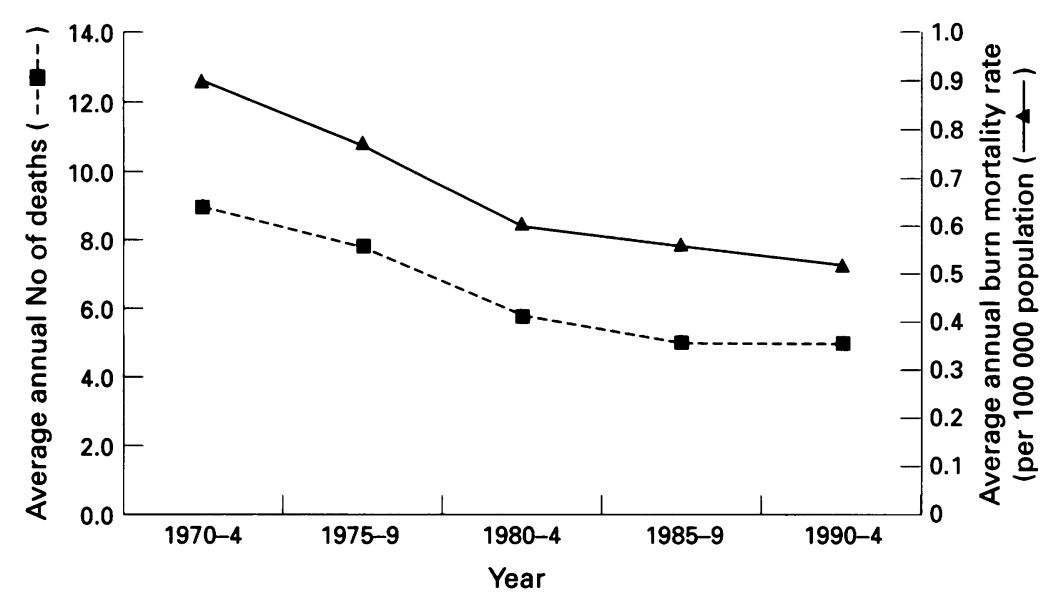

Figure 6 Average annual number of burn deaths in children aged 0-14 years and the corresponding annual burn mortality rate, Victoria, 1970-94.

Table 1 Average age specific number and incidence (per 100 000) for primary burn admissions, Victoria, 1987 and 1994

\begin{tabular}{|c|c|c|c|c|}
\hline $\begin{array}{l}\text { Age } \\
\text { (years) }\end{array}$ & $\begin{array}{l}1987 \\
\text { No }\end{array}$ & $\begin{array}{l}\text { Incidence } \\
(95 \% \text { CI) }\end{array}$ & $\begin{array}{l}1994 \\
\text { No }\end{array}$ & $\begin{array}{l}\text { Incidence } \\
(95 \% C I)\end{array}$ \\
\hline $0-4^{\star}$ & 362 & \multirow{4}{*}{$\begin{array}{l}116.8 \\
(105 \text { to } 129) \\
21.5 \\
(16 \text { to } 27) \\
18.6 \\
(14 \text { to } 23) \\
52.4 \\
(48 \text { to } 57)\end{array}$} & 253 & \multirow{4}{*}{$\begin{array}{l}78.0 \\
(69 \text { to } 88) \\
9.8 \\
(6 \text { to } 13) \\
15.6 \\
(11 \text { to } 20) \\
34.5 \\
(31 \text { to } 38)\end{array}$} \\
\hline $5-9^{\star}$ & 66 & & 32 & \\
\hline $10-14$ & 58 & & 49 & \\
\hline $0-14^{\star}$ & 486 & & 337 & \\
\hline
\end{tabular}

${ }^{\star} \mathrm{p}<0.05$ for incidence by period comparisons for $0-4,5-9$, and $0-14$ age strata.

$\mathrm{CI}=$ confidence interval.

admission numbers during the eight year period. In fact, the proportion of admissions in the 10-14 year age group increased compared with all admissions.

The VIMD also indicated that there has been an apparent increase in the proportion of severe burn admissions. Thirty two per cent of burn admissions were affected by $10 \%$ or more TBSA in 1987 to 1989 , increasing to $36 \%$ of all burns admitted having burns $10 \%$ or more TBSA burned in 1993 to 1994 . This corresponds to a similar trend seen in the Royal Children's Hospital data.

\section{BURNS MORTALITY DATA}

Between 1970 to 1994,163 children aged 014 years were identified to have died from a flame/fire/scald or contact burn during which there was a fall of over $50 \%$ in the number of burn related deaths. In addition, the trend in burn rate mortality fell substantially from 0.9 / 100000 to $0.5 / 100000$, but never reached statistical significance because the sample size was too small (fig 6).

\section{Discussion}

From 1970 to 1994 , the annual number of admissions for all types of burns to the burn unit at the Royal Children's Hospital has shown a substantial downward trend. There has been an apparent increase, however, in the proportion of severe burn admissions. These trends parallel those seen in the VIMD, where a substantial reduction has occurred for all types of burn admissions across the state.

These changes may be interpreted as either a real drop in mild to moderately severe burn presentations, or as a reflection of health service practices leading to a redistribution of burns to regional centres that now have improved capacity to manage mild to moderately severe burns. We believe the most likely explanation is a true fall in the incidence of burns.

Both the hospital and the statewide data support this conclusion. We witnessed a substantial fall in both hospital admissions and statewide mortality rates. In addition, at least for the years 1987 to 1994 , the proportion of burns admitted to the Royal Children's Hospital remained constant in relation to all burn admissions throughout the state. We therefore believe there has been a true fall in burn cases and that referral patterns have not distorted the total number of burn admissions to the hospital or across the state.

We hypothesise that the observed increase in the proportion of severe burns is attributable to two system changes in the management of burn injuries over the past 25 years. In the 1970 s and early 1980 s, there was a substantial improvement in the provision of consultant paediatric and surgical services in suburban and regional Victoria. During this period, children with moderate levels of burn injury were progressively more likely to be managed outside the single tertiary centre. The second phase has occurred over the last 10 years, when greater emphasis on ambulatory management of all injuries, including mild to moderate burns, has taken place. As a result, continued increases in the proportion of severe burns has been witnessed at all levels of hospital care.

A possible limitation of our data is that their accuracy and usefulness varied considerably from year to year. For example, insufficient details recorded in the medical records before 1974 prevented us from coding the source of each burn injury type, and the yearly fluctuations in admission numbers makes it difficult to assess the start of many of the observed trends.

We have made a number of assumptions in using the Royal Children's Hospital and VIMD datasets. The first was that all burn injuries of a certain severity were admitted to hospital and the second was that there was no private sector care given to burns of moderate to severe severity. Due to the expertise available at the hospital burn unit for extensive burns, those treated in private clinics must have been minor. A third assumption was that specialised burn units often reflect changes in referral practices as well as in accident patterns.

How can these trends be explained? It is likely that a combination of legislated standards, improvements in product design and changes in product utilisation, together with an increased awareness of burn injury hazards have all contributed to the observed reductions.

We observed a substantial drop in the three main types of burn injury (scald, flame, and 
Table 2 Key interventions and product safety standards (1970-94)

\begin{tabular}{|c|c|c|}
\hline Design or product & Key intervention or introduced fire safety standard & $\begin{array}{l}\text { Year of } \\
\text { introduction }\end{array}$ \\
\hline $\begin{array}{l}\text { Children's } \\
\text { nightwear }\end{array}$ & $\begin{array}{l}\text { Flammability safety standards for children's nightwear } \\
\text { Safe design practice for children's nightclothes, } \\
\text { AS-CL3 } \\
\text { Care labelling standard of clothing } \\
\text { Children's nightclothes having reduced fire hazard, } \\
\text { AS } 1249-1983 \\
\text { Care labelling standard of clothing, AS 1989-1984 }\end{array}$ & $\begin{array}{l}1969 \\
1976 \\
1983 \\
1984\end{array}$ \\
\hline Product safety & $\begin{array}{l}\text { Banning of firecrackers } \\
\text { Banning of fireworks }\end{array}$ & $\begin{array}{l}1973 \text { and } 74 \\
1982\end{array}$ \\
\hline $\begin{array}{l}\text { Domestic heating } \\
\text { systems }\end{array}$ & $\begin{array}{l}\text { Approval and test specifications for electric room heaters, } \\
\text { AS-C103 } \\
\text { Introduction of central heating } \\
\text { Conventional 'single room heating' phased out and } \\
\text { superseded by central heating } \\
\text { International oil crisis: severely limited the availability of } \\
\text { kerosene and increased the cost of oil } \\
\text { 1990s economic recession forced builders to offer } \\
\text { central heating as a standard heating source }\end{array}$ & $\begin{array}{l}1953 \\
1960 \mathrm{~s} \\
\text { Late } 1960 \mathrm{~s} \\
\text { Early } 1980 \mathrm{~s} \\
1990 \mathrm{~s}\end{array}$ \\
\hline Tap water & $\begin{array}{l}\text { Production of thermostatic tempering valve } \\
\text { Childproof bath hot water tap shields } \\
\text { Manual of authorisation procedures for plumbing and } \\
\text { drainage products, includes the requirement of } \\
\text { thermostatic tempering valve installation } \\
\text { The Australian and New Zealand Burn Association } \\
\text { recommendation of hot water heaters be set at } 55^{\circ} \mathrm{C} \\
\text { Introduction of the Australian National Plumbing } \\
\text { Code AS3500: maximum allowable delivery temperature } \\
\text { of hot water to sanitary fittings not exceed } 50^{\circ} \mathrm{C} \text { and } \\
43^{\circ} \mathrm{C}\end{array}$ & $\begin{array}{l}\text { Late } 1970 \text { s } \\
1990 \\
1993\end{array}$ \\
\hline Household safety & $\begin{array}{l}\text { Care labelling standard of household textiles, furnishings, } \\
\text { upholstered furniture, bedding, piece goods and yarn, } \\
\text { AS 1957-1976 } \\
\text { Portable fire extinguishers safety standards } \\
\text { Domestic smoke detectors: legislation now enforced } \\
\text { for mandatory installation in all new homes as part of } \\
\text { the Victorian Building Code Practices }\end{array}$ & $\begin{array}{l}1976 \\
1980 \\
1986-90\end{array}$ \\
\hline
\end{tabular}

contact burns), but at differing time periods. Between 1990 and 1994 there was a marked reduction in scald related admissions. This may be explained by a reduction in the recommended temperature for new hot water heaters which may have resulted in safer water temperatures (table 2). Although no changes in product design or educational campaign exists for the period 1973 to 1978 to explain the reduction of scald admissions during this period, awareness of burn injuries in Victoria was heightened in the late 1960s with the publication of 'Burns in children: a five-year survey of a burns unit' and the surrounding media publicity. ${ }^{10}$

We also observed differing trends between the causes for individual scald related burn types. For example, a substantial reduction in hot bath or tap water scald related admissions was recorded, while there was a noticeable absence of any decline in the number of scale admissions resulting from hot beverages.

These differences can probably be again explained by changes in product design regulations and standards, which have been actively instituted throughout the state and have contributed greatly to the reduction in paediatric burns (see table 2). The most noted reductions were the decline in tap or bath hot water scalds from the beginning of the 1970 s (fig 2). Childproof bath hot water tap shields, an example of an antiscald product design, were available from the late 1970s. More recent initiatives have included the education of plumbers to recognise the hazards of hot water, the recommendation that the temperature of hot water delivered to residential areas be lowered by using water heaters whose
Table 3 Burns prevention education programs

\begin{tabular}{|c|c|}
\hline Education prevention programs & Year of introduction \\
\hline $\begin{array}{l}\text { - 'Don't Fool With Fuel': Australian } \\
\text { Institute of Petroleum/Royal } \\
\text { Children's Hospital } \\
\text { - 'Hot Water Burns Like Fire': Royal } \\
\text { Children's Hospital } \\
\text { - The Early Childhood Injury Prevention } \\
\text { Program }\end{array}$ & $\begin{array}{l}1978 \text { and } 1981 \\
1984-5 \\
1985-\text { present }\end{array}$ \\
\hline
\end{tabular}

maximum temperature is $50^{\circ} \mathrm{C}$, and the use of temperature limiting devices or safety hof water valves (table 2). In addition there hav\& been intensive efforts by health protectiog programs to educate the public on the dangersof hot tap water exceeding $50^{\circ} \mathrm{C}$ such as the 'Hot Water Burns Like Fire' campaign (table 3) in 1984 or the Early Childhood Injur? Prevention Program (ECIPP). This particulat program involves a discussion with newio mothers of resource and product informatiob that includes burn prevention material. ${ }^{11}$

A large decline in the number of flame burm admissions was also recorded; this was parti $\overrightarrow{\bar{c}}$ cularly marked between 1976 and 1987. Mos of the reduction in flame burns may have beerf effected by changes in indoor heating system $\overrightarrow{8}$ and by the introduction of flammability safety standards for children's nightwear (table 2) Before the 1970s kerosene and other single room, open flame heaters were the most common form of domestic heating. All thesह have been superseded by safer, more sophisti@ cated, and cost efficient heating methods $\overrightarrow{\vec{\sigma}}$ especially central ducted heating. In addition, an education campaign titled 'Don't Fool With Fuel' was introduced by the Australian In? stitute of Petroleum in 1978, and again in 1981.

Of the causes of flame burns, the most noted reductions occurred for those associated wit clothing ignition and indoor heating systems between 1974 and 1991. Changes in standard and regulations of the flammability of chil dren's clothing, and the introduction of label 3 ling of clothing flammability in the mid-1970sis may have been responsible for this. The recognition of the importance of the composio tion and design of children's nightwear, and their association with fire safety, led to the introduction of voluntary flammability safety standards of children's nightwear in 1969. ${ }^{12}$ Classification and labelling of children's nighte clothes for fire hazard were introduced in $1976,{ }^{13}$ and in 1983 mandatory flammabilit. safety standards were introduced. ${ }^{14}$

Another example demonstrating the effec $\stackrel{\Phi}{\Phi}$ tiveness of implementing a legislated standard for product design or the changes in heating practices was the decline of over $50 \%$ ira contact burn admissions, particularly ba क radiator or heater associated contact burns. In 1953, a mandatory safety standard for alf electric bar radiators was introduced requiring the manufacturer to provide a protective guare around the bar. ${ }^{15}$ In addition, the replacemeno of the radiator heater with more sophisticated heating methods, such as ducted heating, have contributed to a drop in contact burns.

An additional key intervention was the banning of fireworks (table 2). There were 23 
firecracker related burn admissions between 1970 to 1981 . Burn injuries from firecrackers disappeared following their prohibition in 1982.

A reduction in house fire related burns was also noted. Factors that may have contributed to this include: the introduction of standards regarding the flammability of fabric for household textiles in $1976^{16}$ (and legislated in 1990), the move away from open flame heating systems, and the improvement in the electrical wiring of housing. In 1986, changes in the Victorian Building Codes required that all new homes have smoke detectors installed.

\section{Conclusion}

In summary, we have witnessed a substantial decline in burn admissions and an appreciable fall for burns of specific causes. These trends are most likely to be attributable to mandatory changes in sleepwear standards and regulations, modifications in heating practices, together with changes in household product safety design. It may also reflect to a lesser extent the success of specific intensive public burn education prevention campaigns, especially those directed towards hot water and flame burns among younger children. Nevertheless, scalds, especially from hot beverages, and flame burns remain the most important causes of burn injuries.

We gratefully acknowledge E Julian Keogh, Director, Burns Centre, Royal Children's Hospital, who generously allowed us to assess the Burns Centre's medical records and provided us with much helpful advice. We thank Ebony Hankinson, Bea with much helpful advice. We thank Ebony Hankinson, Bea Gieinsa, and Janice Grothe for their assistance in preparing the
data. We also thank Tim O'Brien (Brivis Pty Ltd) for supplying data. We also thank Tim O'Brien (Brivis Pty Ltd) for supplying
information regarding the history of central heating developinformation regarding

1 Nolan T, Penny M. Epidemiology of non-intentional injuries in an Australian urban region: results from injury surveillance. $f$ Paediatr Child Health 1992; 28: 27-35.

2 Ngim RCK. Epidemiology of burns in Singapore childrenan 11 year study of 2288 patients. Ann Acad Med 1992; 21: $667-71$.

3 Snelling CFT, Germann ET. Trends in hospital care of burns in Canada. F Trauma 1992; 33: 258-65.

4 van Rijn OJL, Bouter LM, Meertens RM. The aetiology of burns in developed countries: review of the literature. Burns 1989; 15: 217.

5 World Health Organisation. International classification of diseases, 9th revision, clinical modification, (ICD-9-CM). Vol 1: diseases tabular list. Ann Arbor, Michigan: Edward Bol 1: diseases tabular

6 Keogh EJ, Judson RJ, Masterton JP. Protocol for the triage and early management of patients with burn injury in Victoria. Parkville, Victoria: Victorian Medical Postgraduate Foundation, 1994

7 Australian Bureau of Statistics. Estimated age distribution of the populations of Australia, States and Territories, Fune 1971 fune 1976. Canberra: Commonwealth Government Printer, 1971. (Catalogue No. 3201.0.).

8 Australian Bureau of Statistics. Projections of the population of the States and Territories of Australia 1978 to 2011.
Canberra: Commonwealth Government Printer, 1979. (Catalogue No. 3214.0.)

9 Australian Bureau of Statistics. Projections of the populations of Australia States and Territories 1989 to 2031. Canberra: Commonwealth Government Printer, 1990. (Catalogue No. 3222.0.)

10 Biggs JSG, Clarke AM. Burns in children: a five-year survey of a burns unit. Med $f$ Aust 1964; i: 787-92.

11 Horton-James L. Taking on injury-the Early Childhood Injury Prevention Program. Australian fournal of Early Childhood 1992; 17(3): 30-3.

12 Standards Association of Australia. Safe design practice for children's nightclothes, $A S-C L 3$. Australian Standards House, 80 Arthur Street, North Sydney: Standards Association of Australia, 1969.

13 Standards Association of Australia. Classification and labelling of children's nightclothes for fire hazard, AS 1989. Australian Standards House, 80 Arthur Street, North Sydney: Standards Association of Australia, 1976.

14 Standards Association of Australia. Children's nightclothes having reduced fire hazard, AS 1249. Australian Standards having reduced fire hazard, AS 1249. Australian Standards House, 80 Arthur Street, $\mathrm{N}$

15 Standards Association of Australia. Approval and test specifications for electric room heaters, $A S-C 103$. Australian Standards House, 80 Arthur Street, North Sydney: Standards Association of Australia, 1953.

16 Standards Association of Australia. Care labelling of clothing, household textiles, furnishings, upholstered furniture, bedding, piece goods and yarns, AS 1957. Australian Standards House, 80 Arthur Street, North Sydney: Standards Association of Australia, 1976.

Appendix 1 Definitions used for each of the different burn types

BURN TYPE DEFINITIONS USED IN STUDY

Scald Burn sustained from hot liquids such as hot water and steam, hot fats, oils, and foods

Flame Burn sustained from direct contact with an open flame or fire

Contact Burn sustained from direct contact with a hot object

Electrical Burn sustained from direct contact with an electrical contact. May occur as a result of an electrical malfunction or short circuit. Burns caused by contact with an electrical heating element, for example a bar radiator, are not classified as 'electrical' burns but as 'contact' burns

Chemical Burn sustained from direct contact with chemicals

Radiation Burn sustained from exposure to radiation: solar energy, infrared radiation, or electromagnetic ionising radiation

Flash Burn sustained from exposure to the energy produced by explosive material

Friction Burn sustained from the rapid movement of a surface against the skin

\section{Appendix 2}

ICD-9 E codes (external cause of injury), used for this study were E890.0-899.9, E924.0, E924.8, and E924.9. ${ }^{5}$ The coded group of E923, E925, and E926 (accidents caused by explosive material, electric current, and exposure to radiation) were not included since not all injuries coded in these categories are burns. ${ }^{5}$ Also excluded were radiation and electrical burns. 